\title{
CENTRAL DE TUTORIA E MONITORIA: UMA EXPERIÊNCIA INOVADORA EM EAD COM EXCELÊNCIA NO ATENDIMENTO AO ALUNO
}

\author{
FLORIANÓPOLIS/SC MAIO/2018
}

\author{
Ana Paula Gutierrez - DOT - ana.gutierrez@dotgroup.com.br \\ Rafaela Carvalho de Oliveira - DOT - rafaela.oliveira@dotgroup.com.br \\ Sérgio Guardiano Lima - DOT - sergio.lima@dotgroup.com.br \\ Simone Soares Haas Carminatti - DOT - simone.carminatti@dotgroup.com.br \\ Fernanda Cristina da Silva - DOT - fernanda.silva@dotgroup.com.br \\ Tipo: Relato de Experiência Inovadora (EI) \\ Categoria: Métodos e Tecnologias \\ Setor Educacional: EDUCAÇÃO CORPORATIVA
}

\begin{abstract}
RESUMO
O presente artigo descreve a metodologia operacional da Central de Tutoria e Monitoria do DOT digital group como uma experiência sucesso em EaD, com foco na excelência no atendimento e na mediação do processo de ensino-aprendizagem do aluno. São apresentados os agentes envolvidos com a atuação da Central de Tutoria e Monitoria, o papel de cada um no processo e as ferramentas que permitem a realização deste trabalho. O foco está no impacto que essa metodologia operacional, por meio da Central de Tutoria e Monitoria, possui no contato e na aproximação do aluno que estuda a distância, por meio dos seus agentes e da aplicação de diferentes recursos e tecnologias. Para embasar essa atuação, foram realizadas pesquisa descritiva, bibliográfica, documental e observação, que permitem a apresentação de dados e resultados do atendimento e da satisfação dos alunos atendidos pela Central de Tutoria e Monitoria.
\end{abstract}

Palavras-chave: Educação a distância; Tutoria; Monitoria; Excelência; Metodologia Operacional de EaD; Mediação Pedagógica. 


\section{Introdução}

A busca pelo conhecimento e pela aprendizagem contínua é uma realidade na vida da maior parte das pessoas. Atualmente, é preciso que os estudantes complementem seus estudos com atividades extracurriculares; que os profissionais estejam cada vez mais aptos para o competitivo mercado de trabalho; e que os empresários devam estar mais especializados para gerir adequadamente os seus negócios.

Nessa vertente, buscam-se profissionais com uma formação cada vez mais completa, com o domínio técnico em diferentes áreas, como em uma segunda língua, em tecnologias ou, ainda, na própria área em que se pretende atuar. É um consenso que as pessoas devem se aprimorar ao longo de toda vida para que se mantenham atualizadas e, consequentemente, precisam gerenciar seu tempo de forma cada vez mais eficaz.Nesse cenário, a Educação a Distância $(\mathrm{EaD})$ vem ganhando espaço, tanto na educação convencional quanto na corporativa, pois, em razão de suas características, ela torna o acesso e a possibilidade de continuação dos estudos cada vez mais adequados às novas realidades do modo de vida das pessoas.

Todavia, muitos ainda encontram dificuldades em migrar ou iniciar nessa modalidade de ensino por ela apresentar particularidades que se diferenciam do modelo inicial de formação. Entre as particularidades destaca-se a necessidade de disciplina, bem como de competências que nem sempre estão desenvolvidas em todos os alunos. Por essa razão, faz-se necessário que uma equipe de profissionais especializados possa realizar um suporte, pautado em estratégias e metodologias bem definidas, que promova a formação dos alunos de forma plena e significativa. Mais do que um atendimento, serão apresentadas a metodologia operacional e as ações que foram desenvolvidas ao longo de mais de 21 anos pelo DOT digital group para realizar esse acompanhamento e desenvolvimento dos alunos por meio da Central de Tutoria e Monitoria (CTM), que é a base de operação das suas atividades de EdTech.

Nesse contexto, o presente artigo tem como objetivo apresentar a metodologia operacional da Central de Tutoria e Monitoria do DOT digital group, como uma experiência sucesso em EaD, com foco na excelência no atendimento e na mediação do processo de ensino-aprendizagem do aluno. Mais especificamente, será descrita a atuação da CTM na aproximação do aluno que estuda a distância, por meio dos seus agentes, de suas expertises, da aplicação de diferentes recursos e tecnologias, bem como os diferenciais que essa estratégia oferece.

\section{Procedimentos metodológicos}

O presente estudo consiste em uma pesquisa descritiva que traz dados qualitativos e 
quantitativos para representar a realidade do estudo de caso. Para a coleta de dados, foram realizadas pesquisa bibliográfica, documental e observação. Os resultados aqui apresentados evidenciam estratégias utilizadas pelo DOT digital group que podem servir como referência de boas práticas na educação a distância para outros cenários e que, desse modo, poderão contribuir com pesquisadores, estudiosos e profissionais da área.

\section{A educação a distância e o DOT}

A EaD está se propagando cada vez mais como uma modalidade de ensino e a sua disseminação tem feito com que mais pessoas tenham acesso a formações e a um ensino de qualidade. Segundo Cruz, Lima e Padilha (2009, p. 1), ela "vem sendo apontada como uma alternativa eficaz para atender à grande demanda por educação inicial e continuada". Corroborando o exposto pelos autores, Gomes e Assunção (2016) apontam que a EaD tem se revelado um instrumento estratégico e importante de educação continuada para a formação dos diversos tipos de profissionais. Além disso, eles reforçam que esse formato de ensino acaba por apoiar na alavancagem das organizações que buscam sua preservação e inserção em novos espaços em seus mercados.

Essa não é uma realidade exclusiva da educação inicial ou continuada, a EaD está em expansão em praticamente todos os níveis de educação. Um exemplo dessa abrangência é apontado por Santos (2017), que indica que, segundo dados dos censos da Educação Superior, é evidente a ocorrência de um processo de expansão do nível superior pela modalidade EaD. A autora expõe que em 2006 o número de matrículas era inferior a 207.000 alunos, já em 2016, o número chegou a cerca de 1.500 .000 matrículas, uma expansão de mais de $570 \%$ em 10 anos.

Esse aumento se deve também ao fato de que na $\mathrm{EaD}$, ensino e aprendizagem ocorrem sem que os envolvidos estejam no mesmo local e no mesmo momento, o que permite que mais pessoas tenham acesso. Sendo importante ressaltar que essa distância é apenas geográfica, porque eles podem estar conectados pelas mais diversas tecnologias. O DOT digital group vem acompanhando de perto o desenvolvimento da $\mathrm{EaD}$, pelo fato de estar presente neste mercado desde 1996. Por meio dos conhecimentos e experiências adquiridos, a instituição busca criar estratégias com o objetivo de identificar as reais necessidades dos projetos educacionais para desenvolver soluções cada vez mais adequadas dentro desse ramo.

Para facilitar essa conexão, utiliza-se a internet como um dos principais recursos para agilizar todo o processo de aprendizagem, bem como para possibilitar a criação de tecnologias adequadas e atualizadas com o mercado e área acadêmica. Dessa forma, 
entende-se que:

\begin{abstract}
A tecnologia deva estar a serviço da educação, respeitando seus princípios norteadores e trabalhando na evolução de sistemas tecnológicos cada vez mais integrados alicerçados na finalidade social e transformadora que permeiam a educação. A partir desse preceito, objetiva-se criar um processo de educação mais atrativo e efetivo, de forma a acompanhar o novo modus operandi da sociedade atual, sem esquecer do olhar para o futuro, evidenciando um ecossistema sustentável e dinâmico (DOT DIGITAL GROUP, 2017, p. 9).
\end{abstract}

Para proporcionar esse cenário, o DOT aprofunda-se em metodologias essenciais para o desenvolvimento de soluções ligadas à EaD, sendo elas aplicadas a soluções e cursos corporativos, acadêmicos, livres ou de extensão. Para atender de forma personalizada a cada um dos projetos de EaD e às necessidades específicas e gerais de cada um deles, o DOT conta com uma equipe multidisciplinar que vai de ponta a ponta no processo de ensino-aprendizagem. Em muitos casos, essa equipe atua desde a concepção do curso, até a elaboração de seu conteúdo, publicação e, posteriormente, o atendimento dos milhares de alunos por meio de uma Central de Tutoria e Monitoria, a qual representa 0 cerne da estratégia de atendimento em excelência do DOT e que será apresentada na sequência.

\title{
2.1. A Central de Tutoria e Monitoria (CTM)
}

Para atender aos diferentes projetos de educação a distância, é importante compreender, primeiro, que a CTM conta com um grupo de diferentes profissionais cuja atuação extrapola apenas o atendimento aos alunos.

Suas atividades estão abarcadas por um processo de planejamento e organização que se conecta com os objetivos de formação e estão intrínsecas nas diferentes ações. Essas atividades ocorrem desde o processo de concepção, planejamento, execução e acompanhamento dos resultados da formação para o aprimoramento contínuo de suas ações. Isso se deve ao fato de que esses agentes, fazendo parte de todo o processo, não estarão alheios aos resultados e planejamentos futuros. A ideia de construção e reconstrução das ações da CTM é um movimento contínuo, que vai se consolidando ao longo do tempo. Contudo, a CTM está sempre em processo de transformação, buscando melhorar seus resultados.

A CTM utiliza uma estratégia educacional que abrange todas as fases do processo de implantação de uma formação a distância, além de permitir que a satisfação dos alunos em relação aos serviços prestados seja muito bem avaliada. Não há uma hierarquia entre esses agentes que compõem a CTM, na verdade, a atuação de cada um deles se complementa e contribui com as estratégias e ações dos demais. Nessa vertente, cada um dos profissionais possui papéis muito bem definidos dentro da metodologia adotada 
pela CTM. No Quadro 1, é possível compreender melhor quais são esses papéis. Veja:

\section{Quadro 1: Agentes da Central de Tutoria e Monitoria do DOT digital group.}

\begin{tabular}{|c|c|}
\hline Monitoria & $\begin{array}{l}\text { Desenvolve estratégias didáticas que buscam compre ensão e esclare cimento té cnico do } \\
\text { aluno para que este possa realizar seu curso de forma plena, permitindo que seu } \\
\text { aproveitam ento no curso seja ainda mais proveitoso. Cada monitor realiza essas aços nas } \\
\text { tumas atendidas. Está relacionado com todas as questões que envolvem navegaça, } \\
\text { acesso, conclusão e uncionalidades do Ambiente Virtual de Aprendizagem. }\end{array}$ \\
\hline Tutoria & $\begin{array}{l}\text { Da mesma form a que a monitoria, cada tutor atende a um grupo diferenciado de tumas, nas } \\
\text { quais ele utiliza diferentes metodologias e abordagens que garantam que os alunos tenham } \\
\text { maior compreensão e aprofundamento dos conceitos que são tratados ao longo do curso. A } \\
\text { ideia é que esse agente possa potencializar o processo de ensino-aprendizagem por meio de } \\
\text { suas estratégias e mediações, mantendo foco no conteúdo e no conhe cimento. }\end{array}$ \\
\hline
\end{tabular}

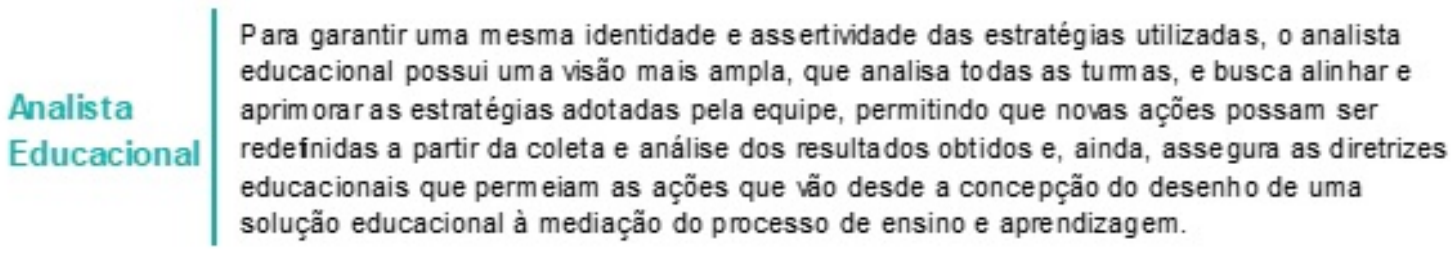

Fonte: Elaboração própria.

Vale ressaltar que as ações desses agentes podem variar de acordo com o projeto de formação, podendo ser adotada uma metodologia pautada principalmente em ações receptivas ou proativas. $\mathrm{Na}$ primeira delas, o atendimento prestado pela monitoria e tutoria assume uma postura em que o contato parte do aluno quando ele sinaliza suas dificuldades, dúvidas e inquietações, trazendo uma reação do monitor ou tutor, que precisa atender ao chamado. Essa é uma postura que se aplica somente ao atendimento, afinal, há um conjunto de ações já planejadas que são executadas de forma proativa, como a delimitação de metas e ações prévias que serão executadas ao longo da formação ou até mesmo a elaboração e a disponibilização de conteúdos que auxiliem na aprendizagem dos alunos.

No formato proativo, tutores, monitores, bem como o analista educacional buscam antecipar possíveis ocorrências que possam surgir dos alunos, para isso, se pautam em dados analíticos que são extraídos do Ambiente Virtual de Aprendizagem (AVA) para analisar o comportamento de um grupo ou até mesmo de um aluno em específico para criar estratégias que possam ajudar na obtenção do sucesso em sua formação. Entretanto, é importante ressaltar que os alunos também podem buscar auxílio sempre que necessário. Independentemente de ser receptiva ou proativa, para que as mediações aconteçam de modo eficaz, é necessário dispor de diferentes ferramentas de informação e comunicação, as quais apresentaremos a seguir buscando relatar seus principais usos e importância no processo de formação dos alunos. 
Antes de abordar as principais ferramentas que são utilizadas pela CTM, faz-se necessário destacar que o uso de cada uma delas está alinhado com os objetivos metodológicos e didáticos previamente definidos, afinal, não há como se valer de uma ferramenta sem que haja um propósito didático em seu uso. Dessa maneira, na metodologia adotada pela CTM, é realizado um planejamento prévio das ações que serão realizadas com foco no perfil dos alunos ao longo da formação, mas sempre estando de acordo com os resultados pedagógicos que se deseja alcançar. A esse planejamento dá-se o nome de Plano de Tutoria e Monitoria (PTM).

Essa metodologia destaca-se para o sucesso atingido nas formações, afinal, é por meio dela que as nuances e os riscos são previamente analisados e, consequentemente, darão meios para a tomada de decisões e planejamento das ações que serão realizadas ao longo da formação. Como prática, esse planejamento se pauta em diferentes dados que podem garantir a efetividade e a personalização das ações, como levar em conta o perfil dos alunos, a duração do curso, os marcos importantes em que o aluno deve se atentar, a assiduidade de cada aluno, a linguagem a ser adotada, a frequência de abordagens, bem como as ferramentas pelas quais essa comunicação se mostrará mais eficiente. Mais do que somente planejar, uma prática adotada pela CTM é analisar ao longo do tempo, de forma contínua, quais são as ações que precisam de maior refinamento para atingir a um número cada vez maior de alunos de forma qualitativa.

Por sua importância e valor agregado, o PTM é desenvolvido de forma colaborativa, em que primeiro há sua concepção, sendo realizada pelo analista educacional, e, posteriormente, recebe contribuições de um membro da equipe de tutoria e monitoria, cada um verificando as ações de modo global e específico.

\subsection{Principais ferramentas utilizadas pela CTM}

O AVA adotado para as formações do DOT é chamado StudiOn, que foi desenvolvido internamente com base nos preceitos metodológicos adotados pela CTM. Nesse AVA, é possível cadastrar as ações que foram arquitetadas nos PTMs elaborados pela CTM. Mais do que isso, é possível realizar seu gerenciamento, podendo gerar novas versões dos PTMs que serão executados ao longo do tempo e que, conforme mencionado anteriormente, permite por meio das análises feitas pela CTM que o PTM seja aprimorado.

Portanto, é possível afirmar que o StudiOn possui uma ferramenta interna em que é possível cadastrar as ações planejadas no PTM que posteriormente ele próprio se encarregará de enviar as ações conforme o planejado. Chamaremos essa ferramenta de PTM-Automatizado, que serve de apoio às ações de larga escala, em que o volume de 
alunos e de cursos atendidos é alto, afinal, uma vez que ela está pronta para executar as ações cadastradas, a CTM não irá se preocupar em realizar as ações previamente planejadas posteriormente ao cadastro. Com isso, o PTM-Automatizado evita que durante a operação uma ou mais ações não sejam realizadas em razão de problemas, como esquecimento, sobrecarga de atividades, descuido ou outros fatores sujeitos de acontecer no dia a dia.

Cabe ressaltar que, durante o cadastro das ações, é possível personalizar o atendimento trazendo variáveis que atendam a um perfil de aluno específico. Sendo assim, é possível, com base nas diferentes variáveis e marcos das formações, programar que ações que já seriam realizadas pela monitoria e tutoria sejam executadas a cada nova oferta de um mesmo curso, possibilitando que a CTM possa focar seus esforços na elaboração de estratégias que assegurem maior sucesso dos alunos em curso.

Além do PTM-Automatizado, existem outros recursos importantes que auxiliam na proatividade de ações da CTM e que colaboram para a diminuição de dúvidas e, até mesmo, na redução de alunos evadidos, como a disponibilização da área de ambientação, o manual do aluno, os tutoriais que auxiliam nos procedimentos técnicos relacionados ao AVA e o plano de estudos. Na área de ambientação, os alunos possuem acesso a um conteúdo explicativo sobre os papéis da tutoria e monitoria, para saber que tipo de dúvidas ele poderá direcionar para cada um deles, quais são os canais de comunicação, como acessar e navegar pelo conteúdo, bem como onde buscar por materiais instrucionais complementares. Segundo Vilarinho e Paro (2011), o módulo de ambientação, intitulado por eles como de acolhimento, atende ao objetivo de promover maior engajamento dos alunos em $\mathrm{EaD}$ e, concomitantemente, minimizar o fenômeno de evasão.

Na biblioteca do curso, o aluno encontra conteúdos instrucionais complementares, como o plano de estudos, em que ele terá acesso aos calendários de eventos previamente agendados no curso, ritmo de estudos sugerido para conseguir finalizar o curso dentro do prazo com sucesso, relação das atividades obrigatórias para a certificação e canais de comunicação. Os tutoriais, que podem ser disponibilizados no formato de vídeos ou arquivo PDF, apresentam conteúdos instrucionais de como realizar uma determinada ação no AVA. Alguns exemplos são: como participar do fórum, enviar dúvidas, entre outros procedimentos. Há ainda a disponibilização do manual do aluno, no qual são apresentados procedimentos internos, uso do AVA, período do semestre letivo, estabelecido no calendário escolar, orientações sobre o processo avaliativo, além de outros esclarecimentos importantes. 
Esses materiais e o PTM-Automatizado já se configuram como ações proativas que são fundamentalmente concebidas e colocadas em prática por meio da metodologia adotada pelo CTM para dar maior chance de os alunos sempre estarem bem informados e amparados pela equipe. São essas ações que darão o embasamento necessário para que os alunos possam ter informações suficientes para adquirir a autonomia que irá permitir a realização dos estudos sem que haja a necessidade de recorrer à monitoria e/ou à tutoria. Além disso, é importante destacar que tais ações permitem um maior engajamento dos alunos para a construção de conhecimentos. E, para realizar a análise e entendimento dos resultados atingidos pelas estratégias adotadas ao longo das formações, a CTM analisa os relatórios e os resultados das pesquisas de satisfação, que apresenta a opinião e satisfação dos alunos referente a diversos aspectos relacionados à formação, possibilitando a extração de dados quantitativos e qualitativos.

Externamente ao AVA, o DOT conta ainda com duas ferramentas que trazem grande diferencial aos atendimentos prestados pela CTM, são elas:

- Ligações telefônicas (0800): realizadas e recebidas pela equipe de monitoria para auxiliar os alunos de modo ágil e personalizado. Disponível entre 08:00 e 18:00 em dias úteis, contudo, há projetos em que esse atendimento se estende até às 21:00 e aos sábados.

- CRM (Costumer Relationship Manager): permite cadastrar, trocar e-mails, manter histórico, direcionar o atendiemnto para o profissional mais indicado etc. Permite o controle, centralização, manutenção de dados e a localização de informações relevantes sobre os atendimentos realizados.

É importante ressaltar que as ligações telefônicas via 0800 são exclusivas para dúvidas de navegação, acesso, informações gerais e demais questões relacionadas ao Ambiente Virtual de Aprendizagem. Assim, é uma ferramenta de uso exclusivo da monitoria. A atuação da Central de Tutoria e Monitoria, na figura dos seus agentes e com o suporte das ferramentas apresentadas, permite que o aluno conte com um apoio preciso e contínuo durante a realização do curso a distância. Ela permite a orientação e a personalização do atendimento de cada estudante, de acordo com as necessidades e particularidades do curso também.

Como é possível notar, a CTM, na figura dos seus agentes e com o suporte das ferramentas apresentadas, possui a capacidade utilizar uma metodologia que busca realizar ações estratégicas direcionadas para promover o processo de ensinoaprendizagem ao longo das formações, contribuindo para a permanência dos alunos em curso e para um maior número de concluintes. 


\section{Apresentação e discussão dos resultados}

Com o intuito de apresentar a dimensão dos resultados alcançados pela Central de Tutoria e Monitoria do DOT digital group, mostra-se necessária a apresentação da consolidação dos dados relativos às formações que contaram com a atuação direta da CTM. Na Tabela 1 são apresentados os dados gerais referentes aos resultados dos projetos entre 2007 a 2017 :

Tabela 1: Dados da atuação do DOT digital group de 2007 a 2017.

\begin{tabular}{lc} 
Dados Consolidados & Quantitativos \\
\hline Cursos & 408 \\
\hline Turmas finalizadas & 5.956 \\
\hline Matriculas & 707.074 \\
\hline Índice de satisfação geral & $95,00 \%$ \\
\hline
\end{tabular}

Fonte: Elaboração própria.

Ao longo de todo o período abrangido, nota-se uma quantidade significativa de alunos matriculados nos cursos oferecidos, maior do que 700.000 matrículas. Analisando esses dados, é fácil notar que a metodologia executada nas formações aplicadas pela CTM do DOT digital group é muito bem avaliada, tendo em vista que a porcentagem de respostas positivas possui uma média muito alta em todos os projetos, sendo de $95 \%$ de satisfação.

Para o presente artigo, acreditamos que o índice de satisfação é o dado de maior relevância entre os apresentados, pois, além de validar todas as estratégias adotadas pela metodologia da CTM, mostra a importância de executar ações previamente planejadas e que se pautam nos objetivos pedagógicos das ações realizadas pela CTM. É importante pontuar que não são contabilizadas as respostas enviadas pelos alunos que se enquadram na categoria "Não utilizei", ou seja, que sinaliza que o aluno não teve um atendimento em determinado canal de comunicação. Assim, com base nos dados apresentados, é possível compreender que a CTM tem um papel fundamental na condução dos cursos EaD, sendo o elo entre o conteúdo/AVA e o aluno.

\section{Considerações finais}

O presente artigo buscou salientar que a EaD vem ganhando cada vez mais espaço no mercado por conta das necessidades de atualizações e qualificações profissionais e pessoais dos indivíduos e, que deste modo, se mostra como uma importante fonte de oportunização de qualificação. Com isso, foi possível apresentar a CTM do DOT digtal group como uma experiência inovadora em EaD, com foco na excelência no atendimento ao aluno. Ademais, destacaram-se o papel da CTM no processo de ensinoaprendizagem dentro da EaD e a necessidade de adoção de estratégias que estejam de 
acordo com os objetivos didáticos das formações a distância.

O case do DOT digital group permite a visualização dos resultados que podem ser obtidos quando, além da CTM, são desenvolvidas ferramentas personalizadas e específicas, como é o caso do StudiOn e do PTM-Automatizado, destacados neste artigo.

Assim, buscou-se demonstrar que a elaboração de ações compatíveis com uma estratégia didática, que funcionem conforme uma metodologia, também são meios de atingir a excelência. Tendo em vista que as ações são planejadas entre os diferentes membros de uma equipe, que se preocupam em elaborar diferentes formas de propiciar maior ganho à aprendizagem dos alunos de forma colaborativa. Dessa forma, conclui-se que o desenvolvimento e a execução de cursos nesta modalidade exigem metodologias educacionais estruturadas e coerentes com os seus tipos cursos, bem como com seus objetivos educacionais. Sendo de suma importância também a dedicação prestada desde a concepção até a operacionalização de formações a distância. Isso fica evidente nos altos índices de satisfação dos alunos e no percentual de concluintes expostos.

\section{Referências}

CRUZ, F. A.; LIMA, T. N.; PADILHA, M. A. S. A visão de alunos sobre o conceito de Educação a Distância e a possibilidade de autonomia e interatividade no ambiente virtual de aprendizagem (AVA). Educação e Aprendizagem. III Simpósio Nacional ABCIBER, 3., 2009, São Paulo. Anais eletrônicos. Pernambuco: Esmp, 2018.

DOT DIGITAL GROUP. O jeito DOT de fazer EdTech. Florianópolis: Instituto de Estudos Avançados, 2017.112 p.

GOMES; L. I. A.; ASSUNÇÃO, J. R. Educação a distância: Uma estratégia de formação continuada no processo de aprimoramento profissional. 9o Encontro Internacional de Formação de Professores, 2016, Sergipe. Anais eletrônicos.

SANTOS, C. A. Educação superior a distância no Brasil: democratização da oferta ou expansão do mercado. RBPAE, Porto Alegre, v. 34, n. 1, p. 167-188, jan.-abr. 2018.

VILARINHO, L. G.; PARO, E. M. Evasão de alunos na educação superior a distância: A experiência do módulo de acolhimento. Voces y silencios. Revista Latinoamericana de Educación, v. 2, n. 2, p. 139-155, 2011. 